\title{
Interleukin 1 and Tumor Necrosis Factor Stimulate Human Vascular Endothelial Cells to Promote Transendothelial Neutrophil Passage
}

\author{
René Moser, Boris Schleiffenbaum, Peter Groscurth, and Jorg Fehr \\ Department of Medicine, Division of Hematology, and Department of Anatomy, Division of Cell Biology, \\ University of Zurich, $\mathrm{CH}-8091$ Zurich, Switzerland
}

\begin{abstract}
In an attempt to understand the regulatory mechanisms governing passage of neutrophils from the vascular bed to the interstitial tissue, we analyzed the effect of the pleiotropic monokines interleukin 1 (IL-1) and tumor necrosis factor (TNF) on transendothelial neutrophil traffic. Short-time preincubation of human umbilical vein endothelial cell (HUVE) monolayers with IL-1 and TNF led to an impressive time- and dose-dependent increase of endothelial cell-associated neutrophils when working in a full plasma system on petri dishes. Electron microscopic analysis revealed junctional penetration of monolayers by neutrophils. More quantitatively, when using a monolayer-on-filter-system, priming led to a severalfold increase in complete layer passage occurring in the absence of an external chemotactic gradient. Direct comparison with an upside-down modification of the system together with data demonstrating the vectorial behavior of such migration revealed that IL-1-stimulated transendothelial neutrophil traffic is polarized. The described enhancement of neutrophil transendothelial passage was found to be a unique feature of IL-1/TNF-activated HUVE since HUVE-dependent transmigration potentiation was not observed as a consequence of mere neutrophil attachment to endothelial cells (e.g., induced by Fcmediated adherence of PMN to HUVE). IL-1 acts selectively on endothelial cells as demonstrated by total inhibition of its effect by actinomycin D. Moreover, IL-1 does not induce HUVE monolayers to secrete a chemotaxin, and the neutrophil passage guiding principle is removable from the HUVE surface by short trypsin exposure. Congruent results were obtained with human adult arterial as well as saphenous vein endothelial cells. As shown by blockade of neutrophil migration with pertussis toxin, IL-1- and TNF-inducible transendothelial migration can be dissected into an initial anchoring step, which is succeeded by active neutrophil migration, possibly along a putative endothelial membrane-bound gradient.
\end{abstract}

\section{Introduction}

Migration through the endothelial cell-basal membrane barrier represents a crucial event during the passage of neutrophils

Presented in part at the 43rd Annual Meeting of the American Federation for Clinical Research, Washington, DC, 3 May 1986 and published in abstract form in 1986. (Clin. Res. 34:502a.)

Address reprint requests to Dr. Fehr, Department of Medicine, A Hof 149, University Hospital, CH-8091 Zurich, Switzerland.

Received for publication 20 November 1987 and in revised form 28 July 1988.

J. Clin. Invest.

(c) The American Society for Clinical Investigation, Inc.

$0021-9738 / 89 / 02 / 0444 / 12 \$ 2.00$

Volume 83, February 1989, 444-455 from the blood stream to the site of inflammation. As a primary step of such complex cell-cell interaction, granulocytes are recruited from the so-called "marginating pool" to adhere to the endothelial cell surface. Numerous in vitro studies have elaborated on the influence of different inflammatory mediators on neutrophil adherence to cultured endothelial cells of different species (1-4). However, adhesion is, in principle, a reversible event, and passage of neutrophils through the vascular cell lining implies penetration of the monolayer through intercellular junctions $(5,6)$. Whether neutrophil emigration is primarily guided by transendothelial chemotactic gradients originating from extravascular inflammatory foci or whether this process is more dependent on a genuine endothelial cellderived activity is still an unsettled issue $(7,8)$. Recent in vivo studies have clearly demonstrated that extracellularly applied inflammatory mediators such as $N$-formylated peptides or C5a are able to localize neutrophils at the injection site (9). On the other hand, the existence of endothelium-derived chemoattractants has also been suggested $(10,11)$. Meanwhile, several recent reports showed increased adhesion of neutrophils to cultured endothelial monolayers that had been pretreated with various inflammatory mediators (leukotriene $B_{4}$, zymosan-activated plasma, IL-1, tumor necrosis factor [TNF]'; 12-16). Furthermore, activation with IL-1 and TNF of endothelial cells was reported to induce cell surface bound structures (17) leading to neutrophil and monocyte attachment (15). However, these studies cannot answer the question as to whether such adhesion is an in vitro model for reversible intravascular neutrophil margination or whether it reflects the first step of cellular emigration. Guided by the morphologically obtained impression that preincubation of human umbilical vein endothelial cell (HUVE) cultures with IL-1 does indeed provoke monolayer penetration by neutrophils, a combined morphologic and functional analysis that might differentiate between simple neutrophil attachment and layer transmigration was undertaken.

\section{Methods}

Preparation of cultured cells. Endothelial cells were obtained from human umbilical cord veins by the method of Jaffe et al. (18), were cultured as described (19), and further propagated in $75-\mathrm{cm}^{2}$ flasks (Falcon Labware, Becton, Dickinson \& Co., Oxnard, CA). Final monolayers used to study neutrophil-endothelium interaction were prepared on $10 \times 35 \mathrm{~mm}$ tissue culture dishes (Falcon). For selected experiments, adult human saphenous vein or arterial endothelial cells, kindly provided by Drs. P. Zilla and R. Fasol (Chir. Universitätsklinik I, Vienna, Austria) as primary cultures isolated from small rests of explants from coronary bypass surgery (20), were propagated, tested for endothelial origin, and used as described above. All culture surfaces

1. Abbreviations used in this paper: ECA, endothelial cell-associated; ECM, extracellular matrix; HIP, heat-inactivated plasma; HUVE, human umbilical vein endothelial cell; TNF, tumor necrosis factor. 
(flasks, dishes, and chambers) were coated with $4 \mu \mathrm{g} / \mathrm{cm}^{2}$ of human fibronectin (19) to improve growth and adhesion of endothelial cells. Monolayers used in this study were completely confluent and in their second to fourth passage; they exhibited positive indirect immunofluorescence with rabbit anti-human Factor VIII antibody. Human lung fibroblasts in their seventh to eighth passage were used for production of extracellular matrix (ECM), and were propagated in $\alpha$-MEM (Gibco Laboratories, Glasgow, Scotland) containing 10\% FCS.

Preparation of endothelial cell monolayers on ECM from human fibroblasts for transmission electron microscopy. ECM from 10- to 12-d-old cultures of human fibroblasts on petri dishes, displaying multilayers of $\sim 50 \mu \mathrm{m}$ thickness, was prepared as described (19). Then, the remaining ECM was incubated with $1 \mathrm{ml}$ of human fibronectin (20 $\mu \mathrm{g} / \mathrm{ml}$ ) for $45 \mathrm{~min}$ at room temperature followed by seeding of HUVE at an 1:2 split ratio.

Preparation of neutrophil suspension and plasma. Venous blood from healthy human donors was collected into $60-\mathrm{ml}$ syringes containing preservative-free sodium heparin $(20 \mathrm{U} / \mathrm{ml}$ blood; Novo Industries, Copenhagen, Denmark). Neutrophils were separated and resuspended in autologous heat-inactivated plasma (HIP, containing $3 \mathrm{U}$ heparin/ml) exactly as described $(21,22)$. For selected experiments, neutrophils, suspended in PBS, were incubated for $2 \mathrm{~h}$ at $37^{\circ} \mathrm{C}$ with 50 $\mathrm{ng} / \mathrm{ml}$ pertussis toxin (List Biological Laboratories, Inc., Campbell, CA). Thereafter, they were sedimented and resuspended in autologous HIP.

Preparation of lymphocyte and erythrocyte suspensions. Mononuclear cells, collected from Ficoll-Hypaque gradients, were washed three times with medium 199 and were allowed to adhere to nylon wool: $6 \mathrm{~g}$ of nylon wool from leukocyte filters (Leuko-Pack; Fenwal Laboratories Inc., Deerfield, IL) were loosely packed into a 20-ml syringe and were flushed three times with $20 \mathrm{ml}$ of medium 199 containing $5 \%$ FCS. Then, the bottom of the syringe was sealed and the mononuclear fraction suspended in medium $199 / 5 \% \mathrm{FCS}\left(10^{7} \mathrm{cells} / \mathrm{ml}\right)$ was added to the syringe and incubated for $2 \mathrm{~h}$ at $37^{\circ} \mathrm{C} / 5 \% \mathrm{CO}_{2}$ at saturated humidity. Thereafter, the syringe was gently flushed with the same medium. The collected cell suspension routinely consisted of $99 \%$ lymphocytes as measured by quantification of CD14-positive cells using the monoclonal antibody MY 4 (Coulter Corp., Hialeah, FL) to check for monocyte contamination using indirect immunofluorescence technique. The vitality of harvested lymphocytes as tested by trypan blue exclusion was $\geq 98 \%$. Erythrocytes were collected from spontaneously sedimented $\left(30 \mathrm{~min}, 20^{\circ} \mathrm{C}\right)$ heparinized venous blood, were washed three times with medium 199 and were then resuspended in autologous HIP.

Quantification of "endothelial cell-associated" (ECA) neutrophils. Confluent endothelial cell monolayers, 6-8 d after seeding on petri dishes $(10 \times 35 \mathrm{~mm})$, were washed twice with $2 \mathrm{ml}$ of PBS containing $0.6 \mathrm{mM} \mathrm{Ca}^{2+}$ and $1 \mathrm{mM} \mathrm{Mg}^{2+}$. Except where stated specifically, they were preincubated with $1 \mathrm{ml}$ of either culture medium or culture medium containing $1 \mathrm{U} / \mathrm{ml} \mathrm{IL-1} \mathrm{(Genzyme} \mathrm{Inc.,} \mathrm{Boston,} \mathrm{MA)} \mathrm{or} 5$ $\mathrm{ng} / \mathrm{ml} \mathrm{TNF}$ (Cetus Corp., Emeryville, CA) for $60 \mathrm{~min}$ at $37^{\circ} \mathrm{C}$. Human recombinant IL- $1 \alpha$ (Hoffmann-La Roche Inc., Nutley, NJ) was used for selected experiments. Monolayers were then washed thrice with 2 $\mathrm{ml}$ of PBS and were overlayered with $4 \times 10^{6}$ neutrophils suspended in $1 \mathrm{ml}$ of autologous HIP. After incubation for $40 \mathrm{~min}$ at $37^{\circ} \mathrm{C}$ and saturated humidity $/ 5 \% \mathrm{CO}_{2}$, monolayers were subjected to a highshear stress wash procedure in order to discriminate between loosely and tightly attached/immigrated neutrophils; they were washed by three rapid circular movements in each of four consecutive beakers containing $300 \mathrm{ml}$ of PBS. Dishes were then dried at $4^{\circ} \mathrm{C}$ and the number of ECA neutrophils was quantified by measuring extracted myeloperoxidase activity as described $(19,23)$. Results of ECA neutrophils are expressed as the percentage of initially applied cells. To assess for shear stress-labile superficial neutrophil adhesion to HUVE, the high-shear stress washing step was omitted and the dishes were simply decanted before quantification of ECA neutrophils (cf. subset of experiments presented in Fig. 11). In certain experiments, protein synthesis of HUVE was blocked by preexposing them to a concentration of $1 \mu \mathrm{g} / \mathrm{ml}$ of actinomycin D (Sigma Chemical Co., St. Louis, MO) for
2 h. For control experiments, HUVE were preincubated with IL-2 (Genzyme Inc.), interferon- $\gamma$ (Schering-Plough Corp., Kenilworth, $\mathrm{NJ}$ ), platelet-derived growth factor (Collaborative Research Inc.), leukotriene B4 (Miles Laboratories, Inc., Elkhart, IN), histamine (Sigma), and thrombin (Collaborative Research Inc., Lexington, MA; preincubation in medium 199 without serum).

For quantification of ECA lymphocytes, the cells suspended in $1 \mathrm{ml}$ medium 199/5\% FCS were labeled with ${ }^{111}$ In: $200 \mu \mathrm{Ci}(\sim 4 \mu \mathrm{l})$ of ${ }^{111}$ In chloride in $0.05 \mathrm{M}$ hydrochloric acid (New England Nuclear Products, Boston, MA) was added to $50 \mu \mathrm{l}$ of a tropolone solution $(2.4 \mathrm{mg} / \mathrm{ml}$ PBS; Serva, Feinbiochimica, Heidelberg, FRG); the total amount of tropolone-complexed ${ }^{11}$ In was then added to lymphocytes suspended in $1 \mathrm{ml}$ of medium $199 / 5 \%$ FCS $\left(10^{7}\right.$ cells $\left./ \mathrm{ml}\right)$. After incubation at room temperature for $15 \mathrm{~min}$, the labeled lymphocytes were washed three times with medium 199/5\% FCS and were finally resuspended in autologous HIP $\left(2 \times 10^{6}\right.$ cells $\left./ \mathrm{ml}\right)$.

Assessment of neutrophil secondary granule release and hexose monophosphate shunt activity. Vitamin $\mathrm{B}_{12}$ binding protein (B12BP), a sensitive marker for release of secondary granule constituents, was measured by the relative absorption of $\left[{ }^{57} \mathrm{Co}\right] \mathrm{B}_{12}(21,22)$. To calculate the fraction of total cellular B12BP released, neutrophils suspended in HIP were frozen-thawed three times after adding $0.5 \%$ Triton $\mathrm{X}-100$. The hexose monophosphate shunt activity of $4 \times 10^{6}$ neutrophils on HUVE stimulated with IL-1 $(1 \mathrm{U} / \mathrm{ml})$ was determined by measuring generation of ${ }^{14} \mathrm{CO}_{2}$ from $\left[1-{ }^{14} \mathrm{C}\right]$ glucose $(22)$ and was assessed concomitantly with the determination of ECA-neutrophils and B12BP release under identical conditions with the same cell batches.

Morphologic analysis of neutrophil-endothelial cell interaction assessed by transmission and scanning electron microscopy (EM). Endothelial cells grown on ECM of human fibroblasts (for transmission EM) or on Nuclepore membranes mounted on Boyden chambers (for scanning EM) were pretreated with IL-1 or TNF, incubated with 1 $\times 10^{6}$ neutrophils as outlined above (cf. Determination of ECA neutrophils) and were then overlayered four times with PBS. For transmission EM, the specimens were prefixed with $0.8 \%$ paraformaldehyde/ $2 \%$ glutaraldehyde in $0.05 \mathrm{M}$ cacodylate buffer and postfixed with aqueous solution of $1 \% \mathrm{OsO}_{4}$ containing $1.5 \% \mathrm{~K}_{4}(\mathrm{FeCN})_{6}$. Subsequently, the samples were dehydrated in ethanol and embedded into epon on reversed beam capsules. Ultrathin sections, perpendicular to endothelial cells, were contrasted with uranyl acetate and lead citrate and were studied with a transmission electron microscope (TEM 420; Philips Electronic Instruments, Mahwah, NJ). For scanning EM studies, the specimens were fixed successively in $2 \%$ glutaraldehyde, $1 \%$ $\mathrm{OsO}_{4}, 1 \%$ tannic acid, and $2.5 \%$ uranyl acetate as described (24). After dehydration in acetone, the specimens were dried by the critical point method, mounted on aluminum stubs and sputter coated with gold ( 10 $\mathrm{nm}$ ) using sputter pulse control. The preparations were then examined with a scanning electron microscope (SEM 505; Philips).

Neutrophil migration through endothelial cell monolayers. Endothelial cells were seeded on Nuclepore polycarbonate membrane filters ( $5 \mu \mathrm{m}$ pore size; Nuclepore Corp., Pleasanton, CA) that were welded on modified Boyden chambers with an inner diameter of $9 \mathrm{~mm}$ (upright system). To elucidate polarization of the IL-1-induced transendothelial neutrophil migration, HUVE were grown on the lower surface of the membrane (inverted system) by keeping the upper part of chambers in an upside-down position during culturing. $1 \mathrm{wk}$ after seeding, each batch was tested for confluence by toluidine blue staining followed by microscopic control. The cultures were then washed twice with PBS $(0.5 \mathrm{ml})$ and were preincubated with either medium (control) or monokines (IL-1, $1 \mathrm{U} / \mathrm{ml}$; TNF $5 \mathrm{ng} / \mathrm{ml}$ ) for $60 \mathrm{~min}$ at $37^{\circ} \mathrm{C}$. Thereafter, the cultures were rinsed five times with $0.5 \mathrm{ml}$ of PBS, transferred upside-down into Boyden chambers that contained in their lower compartment $0.6 \mathrm{ml}$ of either HIP alone or HIP plus $1 \times 10^{-8} \mathrm{M}$ FMLP (Bachem AG, Bubendorf, Switzerland) or C5a (purified to homogeneity; 25, 26) as chemotactic agents. $1 \times 10^{6}$ neutrophils in $1 \mathrm{ml}$ HIP were then added to the upper compartment. For selected experiments, rabbit anti-human $\beta_{2}$-microglobulin antibody (Dako, Copenhagen, DK), previously dialyzed against PBS, was added to the upper 
compartment at a final dilution of 1:50. After incubation for $90 \mathrm{~min}$, migration was stopped by addition of $25 \mu \mathrm{l}$ of $0.2 \mathrm{M}$ Na-EDTA solution to the lower and upper compartment of the chamber. Detachment of neutrophils that had passed to the lower surface of the filter was completed by gentle shaking. The loosened neutrophils in the lower compartment were then resuspended thoroughly and were counted manually in a blind fashion using a Neubauer counting chamber. Dependence of neutrophil layer penetration on endothelial protein synthesis was also tested in this experimental model. HUVE layers were preincubated with actinomycin D (Sigma; $1 \mu \mathrm{g} / \mathrm{ml}$ ) for $1 \mathrm{~h}$. IL-1 $(1 \mathrm{U} / \mathrm{ml})$ was then added and the incubation proceeded for another hour before HUVE cultures were washed three times with $500 \mu l$ of PBS. Actinomycin D at the above concentration had no influence on random or chemotactic migration of neutrophils. To control for IL-1or TNF-induced unspecific leakiness of HUVE, untreated and IL-1/ TNF-primed layers were tested for penetration by lymphocytes (1 $\left.\times 10^{6}\right)$ and erythrocytes $\left(1 \times 10^{7}\right)$, with the experimental procedure identical to the one applied for neutrophils except that the detachment step with Na-EDTA was omitted.

In order to test for the possibility that stimulated HUVE monolayers might secrete chemoattractants, the system was modified as follows: HUVE monolayers were grown in 24-well plates, were activated with IL-1 or TNF as indicated, were then washed thrice with $1 \mathrm{ml}$ PBS and overlayered with HIP or HIP containing FMLP $\left(10^{-8} \mathrm{M}\right)$. Using the same compartment volumes as indicated above but adding 7 $\times 10^{6}$ neutrophils to the upper compartment, the Boyden chambers fitted with an uncoated nitrocellulose micropore filter $(8-\mu \mathrm{m}$ pore size, filter thickness $120 \mu \mathrm{m}$; Sartorius Inc., Göttingen, GDR) were hung over these HUVE monolayers. The migration assay was carried out as described above except that the number of neutrophils migrating through the filter into the bottom compartment was quantified by measuring extracted myeloperoxidase activity.

${ }^{125}$ I-albumin permeability of HUVE-monolayers. ${ }^{125} \mathrm{I}$-albumin (Amersham International, Buckinghamshire, England) in HIP was added to the upper compartment of IL-1- or TNF-activated HUVE grown on micropore filters of Boyden chambers. The procedure for the permeability assay was as described for HUVE transmigration of neutrophils omitting the final neutrophil detachment step. Permeability was calculated in percentage of maximal achievable counts at equilibrium.

Flow cytometry. For these experiments, HUVE monolayers were washed twice with PBS and preincubated with $1 \mathrm{ml}$ of either culture medium or medium containing $1 \mathrm{U} / \mathrm{ml} \mathrm{IL-1}$ for $120 \mathrm{~min}$ at $37^{\circ} \mathrm{C}$. They were then washed twice and overlayered with $4 \times 10^{6}$ neutrophils suspended in $1 \mathrm{ml}$ of autologous HIP. For the cytofluorometric determination of Mac-1 (CD11b/CD18) surface expression, PMN in PBS supplemented with $5 \mathrm{mg} / \mathrm{ml}$ of human albumin (ORHA 20/21; Behringwerke AG, Marburg, FRG; PBS-A) were either left unstimulated or were stimulated by FMLP $\left(2.5 \times 10^{-6} \mathrm{M}, 37^{\circ} \mathrm{C}\right)$ and let to adhere to plastic tissue culture dishes to increase Mac-1 surface expression maximally. They were then gently removed from the plastic surface by a rubber policeman (adherent subpopulation only), washed twice in PBS-A, were resuspended in HIP and coincubated for $30 \mathrm{~min}$ at $37^{\circ} \mathrm{C}$ with HUVE monolayers that had either been preincubated for $1 \mathrm{~h}$ with IL-1 $(1 \mathrm{U} / \mathrm{ml})$ or not. Thereafter, the percentage of ECA neutrophils was determined using our standard procedure. All adherence experiments, for quantification of ECA neutrophils and cytofluorometry were made in parallel under identical conditions and were verified by phase-contrast microscopy. For cytofluorometry, ECA neutrophils together with the endothelial monolayer itself were carefully removed from plastic dishes by a rubber policeman, and were cooled to $4^{\circ} \mathrm{C}$. The cells were monodispersed as verified by phase-contrast microscopy by passing the cell suspension several times gently through the opening of a $10 \mathrm{ml}$ pipette (Falcon Labware), were centrifuged $\left(4^{\circ} \mathrm{C}, 200 \mathrm{~g}\right)$ and resuspended at $5 \times 10^{5} \mathrm{PMN} / \mathrm{ml}$ in $1 \mathrm{ml}$ PBS-A. They were washed once in ice-cold PBS-A and were resuspended in $50 \mu \mathrm{l}$ PBS-A containing the primary antibody. Incubation was continued for $60 \mathrm{~min}$ at $4^{\circ} \mathrm{C}$. After two washes with ice-cold PBS-A, the cells were reincubated for $30 \mathrm{~min}$ in $50 \mu \mathrm{l}$ of the same buffer containing fluorescein-conjugated goat anti-mouse-IgG antibody (Tago, Inc., Burlingame, CA) at a saturating concentration of the secondary antibody. The cells were washed twice again, controlled for vitality (trypan-blue exclusion: $>88 \%$ unstained), and fixed in $1 \%$ paraformaldehyde in PBS-A. The cells were washed again and kept in PBS-A at $4^{\circ} \mathrm{C}$ overnight. Cytofluorometry was carried out within $12 \mathrm{~h}$ using a cytofluorograph ( $50 \mathrm{H}$; Ortho Diagnostic Systems Inc., Raritan, NJ).

Fluorescence intensity was determined directly on a linear scale and is reported herein as the mean fluorescent channel with 20,000 cells examined for each determination. Specific fluorescence was calculated by subtracting the mean fluorescent channel of cells that had been reacted with a negative control antibody directed towards an antigen not present on granulocytes (MAS144p). Peak fluorescence channel measurements carried out in parallel showed similar results. In addition, cells were checked under the fluorescence microscope. Monoclonal antibody (MAb) 60.3 (anti Mac-1 $\beta$-chain, CD 18, $\operatorname{IgG}_{2 a}$ ) was kindly provided by Dr. M. Patarroyo, Department of Immunology, Karolinska Institute, Stockholm, Sweden. This antibody reacts with the common $\beta$-chain of Mac-1 (CD 11b/CD 18), LFA-1 (CD $11 \mathrm{a} / \mathrm{CD} 18$ ), and glycoprotein 150/95 (CD 11c/CD 18). Since expression of the two latter heterodimers on granulocytes is low (27), most of the $\beta$-chain on these cells is associated to $\alpha$-M (CD 11b). Monoclonal antibody $\mathrm{M} 1 / 70$ (anti-Mac-1 $\alpha$-chain, $\mathrm{CD} 11 \mathrm{~b}, \mathrm{IgG}_{2 \mathrm{~b}}$ ) was purchased from Hybritech, Inc., San Diego, CA. These MAb were used at a saturating concentration of $10 \mu \mathrm{g} / \mathrm{ml}$ as determined cytofluorometrically.

\section{Results}

As comparatively depicted in Fig. $1, A$ and $C$ by phase contrast microscopy and quantitatively in Fig. $1 E$, preincubation $(60$ $\min / 37^{\circ} \mathrm{C}$ ) of confluent HUVE monolayers on tissue culture dishes with IL-1 or TNF followed by coincubation of neutrophils $\left(40 \mathrm{~min} / 37^{\circ} \mathrm{C}\right)$ suspended in autologous plasma led to a significant increase in ECA neutrophils. Starting at a baseline of $0-5 \%$ ECA neutrophils, a significant increase was already observed after HUVE preincubation with $0.05 \mathrm{U} \mathrm{IL}-1 / \mathrm{ml}$, and a maximum was reached at $1-5 \mathrm{U} / \mathrm{ml}$ corresponding to 20-80\% ECA neutrophils when quantified by myeloperoxidase extraction (maximum variable between different HUVE batches).

To characterize the nature of IL-1-induced neutrophil-endothelial interaction on a morphologic basis, extensive EM studies were carried out. Semithin sections of HUVE layers cultured on ECM of human fibroblasts revealed deep subendothelial penetration of neutrophils migrating through IL-1 primed HUVE (Fig. $1 D$ ), whereas control experiments showed hardly any infiltration (Fig. $1 B$ ). Scanning EM of IL-1-activated HUVE monolayers grown on micropore filters revealed polarized neutrophils often displaying marginal folds extending at the surface of endothelial cells (Fig. $2 \mathrm{~A}$ ). Neutrophils were often found at the cellular margin of endothelial cells exhibiting pseudopod-like processes projecting between two adjacent endothelial cells (Fig. $2 B$ ). When lower surfaces of micropore filters from migration experiments through IL-1-challenged HUVE monolayers were viewed, numerous extremely polarized neutrophils could be found (Fig. $2 C$ ). Transmission EM displayed clear tendency for transendothelial passage of neutrophils at intercellular junctions (Fig. 3, A and $B$ ). There were no signs of neutrophil degranulation and lysis of extracellular matrix by penetrated subendothelial neutrophils (Fig. $3 B$ ). The use of TNF ( 5 and $50 \mathrm{ng} / \mathrm{ml}$ ) instead of IL-1 as an endothelial activator led to identical morphological 

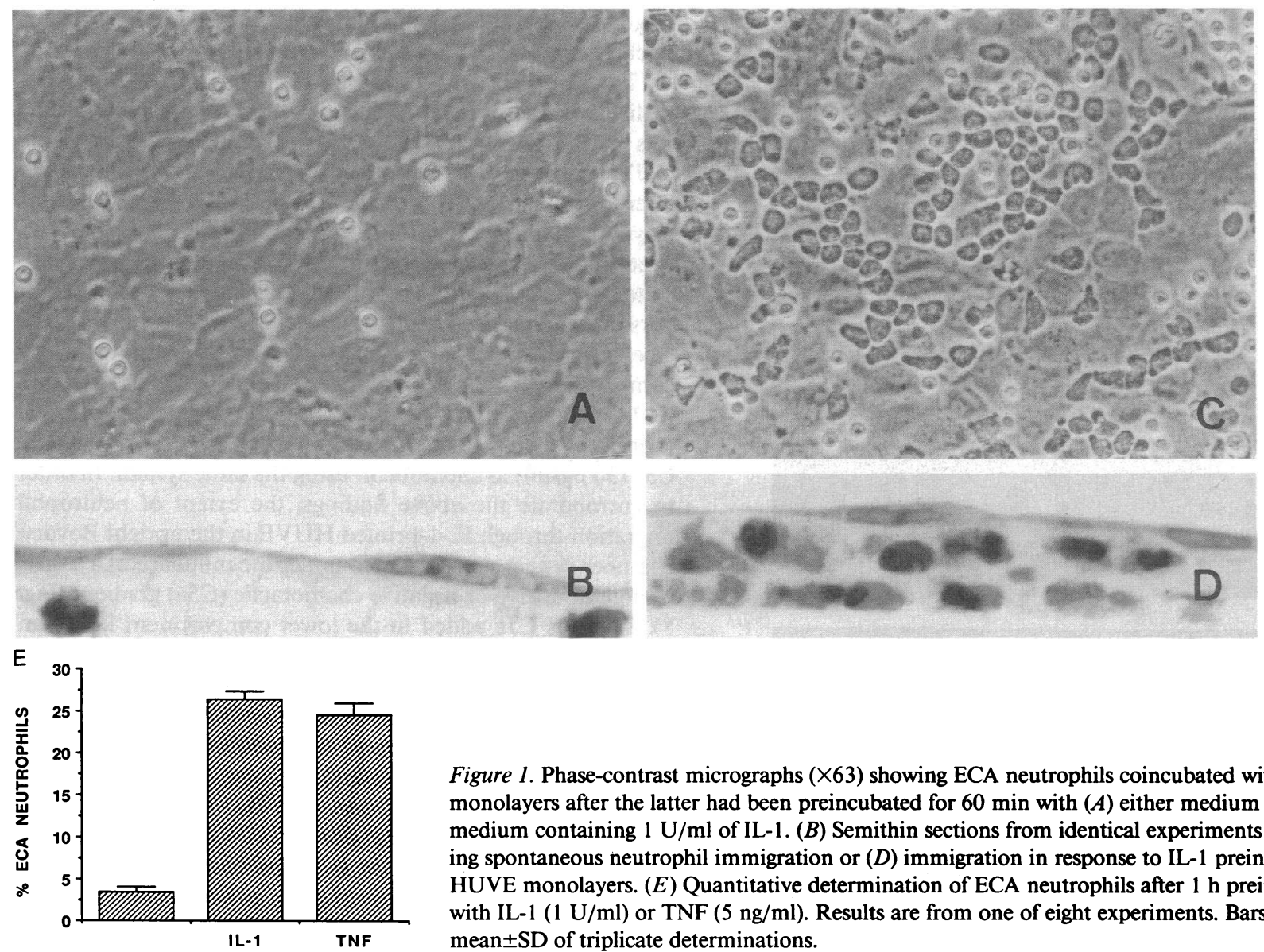

Figure 1. Phase-contrast micrographs $(\times 63)$ showing ECA neutrophils coincubated with HUVE monolayers after the latter had been preincubated for 60 min with $(A)$ either medium alone or $(C)$ medium containing $1 \mathrm{U} / \mathrm{ml}$ of IL-1. (B) Semithin sections from identical experiments demonstrating spontaneous neutrophil immigration or $(D)$ immigration in response to IL-1 preincubation of HUVE monolayers. $(E)$ Quantitative determination of ECA neutrophils after $1 \mathrm{~h}$ preincubation with IL-1 $(1 \mathrm{U} / \mathrm{ml})$ or TNF $(5 \mathrm{ng} / \mathrm{ml})$. Results are from one of eight experiments. Bars denote mean $\pm \mathrm{SD}$ of triplicate determinations.

results. Moreover, endothelial cells as well as their intercellular junctions appeared morphologically unchanged following activation by IL-1 or TNF at the indicated concentrations.

To allow for better quantification of complete layer transmigration by neutrophils, a system using HUVE grown to confluence on micropore membranes mounted into Boyden chambers was adopted (28). As depicted in Fig. 4, challenge of HUVE monolayers by IL-1 resulted in a considerable increase of neutrophil transendothelial passage in the absence of a chemotactic gradient that was comparable to the chemotactic response toward $1 \times 10^{-8} \mathrm{M}$ FMLP (or C5a, $50 \mathrm{ng} / \mathrm{ml}$; Fig. 8). Time course experiments further underline that endotheliumprovoked transmigration is almost reaching the level of FMLP-induced chemotactic migration (Fig. $5 \mathrm{~A}$ ). Searching for the optimal preincubation time, HUVE monolayers, in the dish assay as well as in the modified Boyden chamber system, were preincubated with either IL-1 $(2 \mathrm{U} / \mathrm{ml})$ or TNF (50 $\mathrm{ng} / \mathrm{ml}$ ) for variable periods. In both systems congruent results were obtained characterized by a rather linear increase between 0 and $120 \mathrm{~min}$ and peaking at $6 \mathrm{~h}$ of preincubation time (Fig. 5, $B$ and $C$ ). To evaluate for the minimal effective HUVE priming time, layers were exposed for 1-60 min to IL-1 (1 $\mathrm{U} / \mathrm{ml}$ ); they were then washed and kept at $37^{\circ} \mathrm{C}$ to reach an uniform total preincubation time of $60 \mathrm{~min}$ before neutrophils were added. IL-1 priming of HUVE for 1-5 min was already effective and a linear increase was observed between 1 and 60 min. Identical results were obtained when using human saphenous vein or arterial endothelial cells.
The assumption that promotion of neutrophil layer penetration could simply result from increased attachment of these cells to the endothelial cell lining necessitated the following series of experiments. Simultaneous comparison of binding in the HUVE dish assay with transmigration using the monolayer-on-filter system revealed increased attachment as well as transmigration by IL-1 priming of HUVE, but only binding promotion without enhanced layer penetration in the case of Fc-mediated attachment of neutrophils to antibody-coated HUVE (rabbit anti-human- $\beta_{2}$-microglobulin antibodies; Fig. 6). Moreover, thrombin, described to enhance neutrophil adhesion to endothelium after short time priming of the latter resulted in a shear stress-labile surface interaction and was not accompanied by enhanced neutrophil layer penetration (Table II). Nomarski phase-contrast microscopy supported the above results displaying nonpolarized superficial neutrophils clearly different from polarized cells showing junctional penetration when HUVE were primed with TNF and IL-1. The same was the case when an adhesion promoting concentration of FMLP $\left(2.5 \times 10^{-6} \mathrm{M}\right)$ was present during the HUVE/neutrophil coincubation step (data not shown).

The question as to whether a chemotaxin released by IL-1primed HUVE could be responsible for increased neutrophil layer penetration led to the following experiment: modified Boyden chambers, equipped with $8-\mu \mathrm{m}$ pore size nitrocellulose membranes (thickness $120 \mu \mathrm{m}$ ), were hung over IL-1primed HUVE monolayers grown in 24-well plates (see Methods). The percentage of migrated neutrophils in a $90-\mathrm{min}$ 

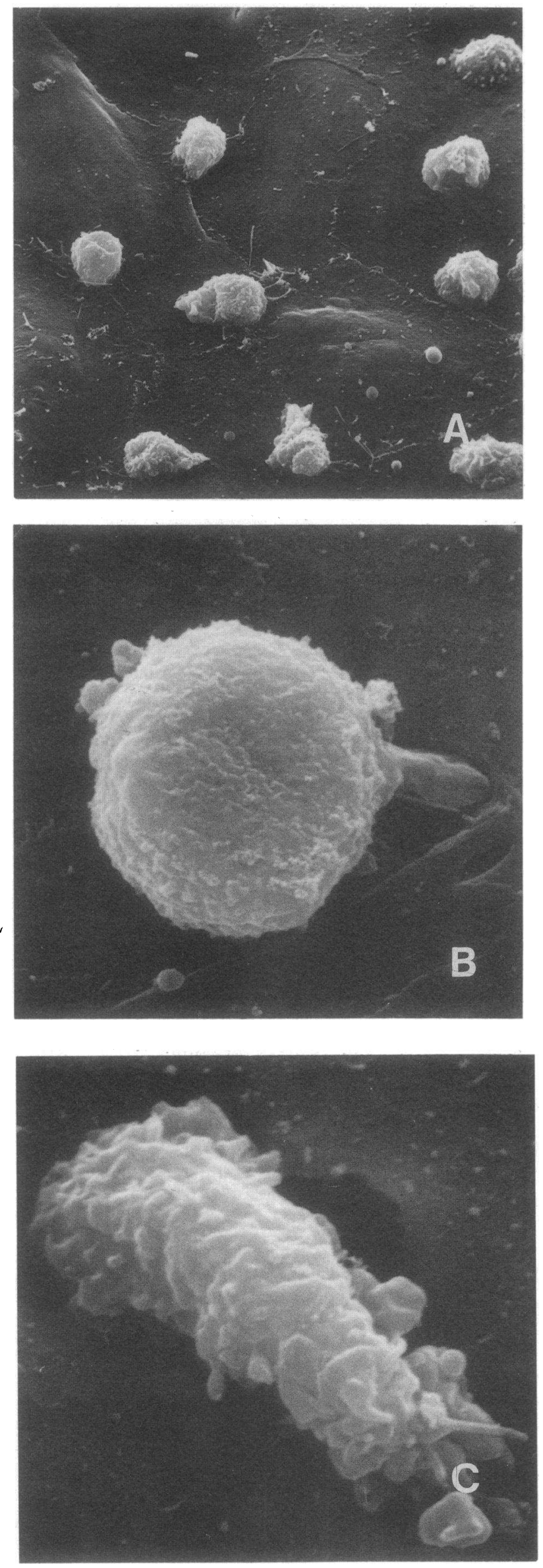

migration assay revealed no difference for IL-1-challenged vs. unchallenged HUVE monolayers (Table I).

To evaluate for polarization of IL-1-induced transendothelial migration of neutrophils, the monolayer-on-filter assay was compared with its upside-down modification culturing HUVE to confluency on the lower surface of the micropore filter which separates upper and lower compartments of the Boyden chamber (inverted system). Whereas random and chemotaxin-stimulated migration was comparable in both systems, HUVE priming with IL-1 led only in the upright version to enhanced neutrophil layer penetration (Fig. 7). Chemotactic response to FMLP $\left(10^{-8} \mathrm{M}\right)$ added to the lower compartment of upright and inverted chambers together with IL-1 activation of HUVE gave proof of preserved neutrophil motility in both systems. Congruent results were obtained with $\mathrm{C} 5 \mathrm{a}(50 \mathrm{ng} / \mathrm{ml})$ as chemotaxin using the same system. In order to corroborate the above findings, the extent of neutrophil migration through IL-1-primed HUVE in the upright Boyden chamber system was estimated under the influence of a superimposed positive or negative chemotactic (C5a) gradient (Fig. 8). Whereas C5a added to the lower compartment led to an additive migration behavior, IL-1 stimulation of HUVE was able to counteract a negative chemotactic gradient when C5a was placed in the upper part of the chamber.

Our following data support the endothelial origin of provoked neutrophil transmigration: $(a)$ congruent results are obtained when HUVE are primed with IL-1 $(1 \mathrm{U} / \mathrm{ml})$ or when the stimulus remains present during HUVE-neutrophil interaction; $(b)$ the presence of the RNA/protein synthesis blocker actinomycin $\mathrm{D}(1 \mu \mathrm{g} / \mathrm{ml})$ during the preincubation step inhibits the IL-1 effect by $94.5 \pm 6.5 \%$ when tested in the dish assay (results from four separate experiments; cf. inhibition of $87 \%$ in the monolayer-on-filter system, Fig. 4); (c) exposure of IL-1-challenged HUVE to trypsin $(0.05 \mathrm{mg} / \mathrm{ml}$ for $1 \mathrm{~min})$ reduces transmigration by $>76 \%$; $(d)$ most noticeable, IL-1 $(0.01-10 \mathrm{U} / \mathrm{ml})$ is devoid of any stimulatory activity on neutrophils when tested in our established assays for chemotaxis, adhesion, and granule release (21). IL-1 acts identically whether it is added to HUVE in buffer, fresh plasma or heatinactivated plasma. Furthermore, nonglycosylated human recombinant IL- $1 \alpha$ could substitute for the monocyte-produced IL-1. Endotoxin as a potential contaminant is excluded by the fact that heat $\left(70^{\circ} \mathrm{C} / 30 \mathrm{~min} ; 29\right)$ selectively and completely destroys IL- 1 activity $\left(56^{\circ} \mathrm{C} / 30\right.$ min resulted in $96 \pm 2 \%$ inhibition), whereas addition of polymyxin $B(50 \mu \mathrm{g} / \mathrm{ml})$ to the assay had no effect $(0 \pm 3 \%$ inhibition; $n=3)$. Blocking prostaglandin metabolism by indomethacin ( $\leq 500 \mu \mathrm{g} / \mathrm{ml}$ ) had no impeding effect on the above described phenomenon. Likewise, IL-1-induced neutrophil transmigration was not influenced by highdose corticosteroids; this was the case when methylprednisolone $(\leq 20 \mu \mathrm{g} / \mathrm{ml})$ was present up to $4 \mathrm{~h}$ before and during the IL-1 priming phase as well as when it was added to neutrophils in the coincubation phase.

Figure 2. Interaction of neutrophils with IL-1-activated HUVE monolayers on Nuclepore membranes (5- $\mu \mathrm{m}$ pore size). (A) Polarized neutrophils with broad membrane folds attached to the surface of endothelial cells $(\times 1,100)$. (B) Neutrophil with pseudopod projecting between two endothelial cells $(\times 4,600)$. $(C)$ Polarized neutrophil on the neat lower surface of a Nuclepore membrane following transmigration through an IL-1-activated HUVE-monolayer $(\times 4,600)$. 

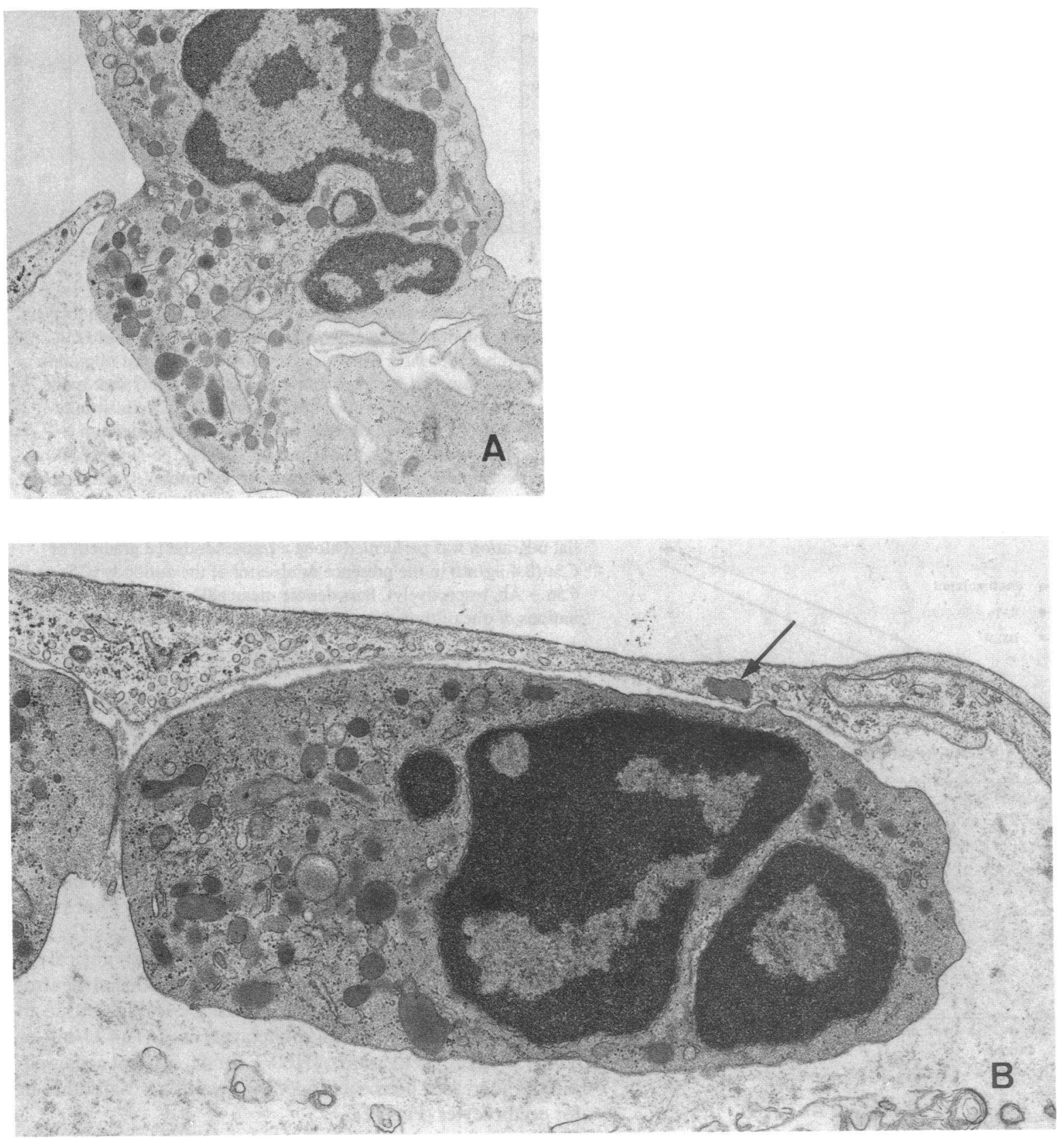

Figure 3. Invasion of a neutrophil between endothelial cells stimulated with IL-1 (1 U/ml). $(A)$ Neutrophil invading between two adjacent endothelial cells $(\times 12,000)$. $(B)$ Transmigrated neutrophil in the subendothelial extracellular matrix (ECM) from human fibroblasts. No signs of neutrophil granule release and pericellular lysis are present (arrow points to a Weibel-Palladebody).

To address the question of IL-1-specificity, different defined cytokines and inflammatory mediators were tested for their ability to provoke a shear stress-stable association of neutrophils to HUVE in the dish assay (Table II). Such studies revealed TNF as at least as active as IL-1 (see also Fig. 4 and Fig. $5 C$ ), whereas a series of other compounds were found to be inactive.

Looking at metabolic activities of ECA neutrophils, IL-1induced augmentation of ECA neutrophils (Fig. $9 \mathrm{~A}$ ) was not accompanied by respiratory burst activation (Fig. $9 \mathrm{C}$ ) or enhanced release of secondary granule constituents (Fig. $9 \mathrm{~B}$ ). Putative activation of neutrophils during interaction with IL-1-activated HUVE was further tested by cytofluorometric determination of Mac-1-complex expression on the surface of interacting neutrophils. Despite a massive increase in ECA neutrophils, significant upregulation of Mac-1 surface expression was not observed (Fig. 10).

The following experiments allow us to dissect mere cell attachment from endothelium-governed cellular transmigration of HUVE.

The ability of neutrophils to migrate was completely blocked by pretreatment with pertussis toxin $(50 \mathrm{ng} / \mathrm{ml}$ for $2 \mathrm{~h}$ at $37^{\circ} \mathrm{C} ; 30$ ). Such neutrophils were still able to bind to IL-1activated HUVE, although it occurred in a shear stress-labile manner, whereas binding of untreated neutrophils was shear stress-stable (Fig. 11). This type of experiment separates endo- 


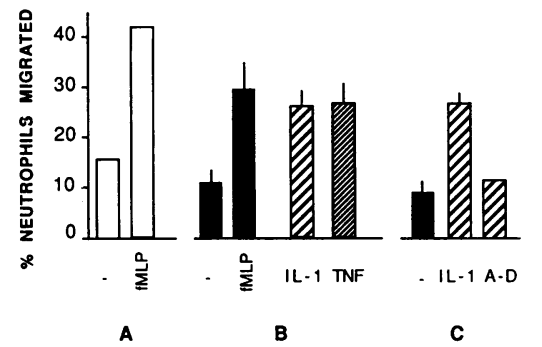

dom migration ( across unstimulated HUVE-monolayers compared to random migration across IL-1 $(1 \mathrm{U} / \mathrm{ml})$ - and TNF $(5 \mathrm{ng} / \mathrm{ml})$-activated endothelium. (C) Random migration across unstimulated (-), IL-1 activated (IL-1) and IL-1 activated endothelium with de novo protein synthesis blocked by actinomycin $\mathrm{D}(\mathrm{A}-\mathrm{D}, 1 \mu \mathrm{g} / \mathrm{ml})$. Bars denote mean \pm SD of triplicate determinations of one of six identical experiments (SD $<1 \%$ of mean are not shown).
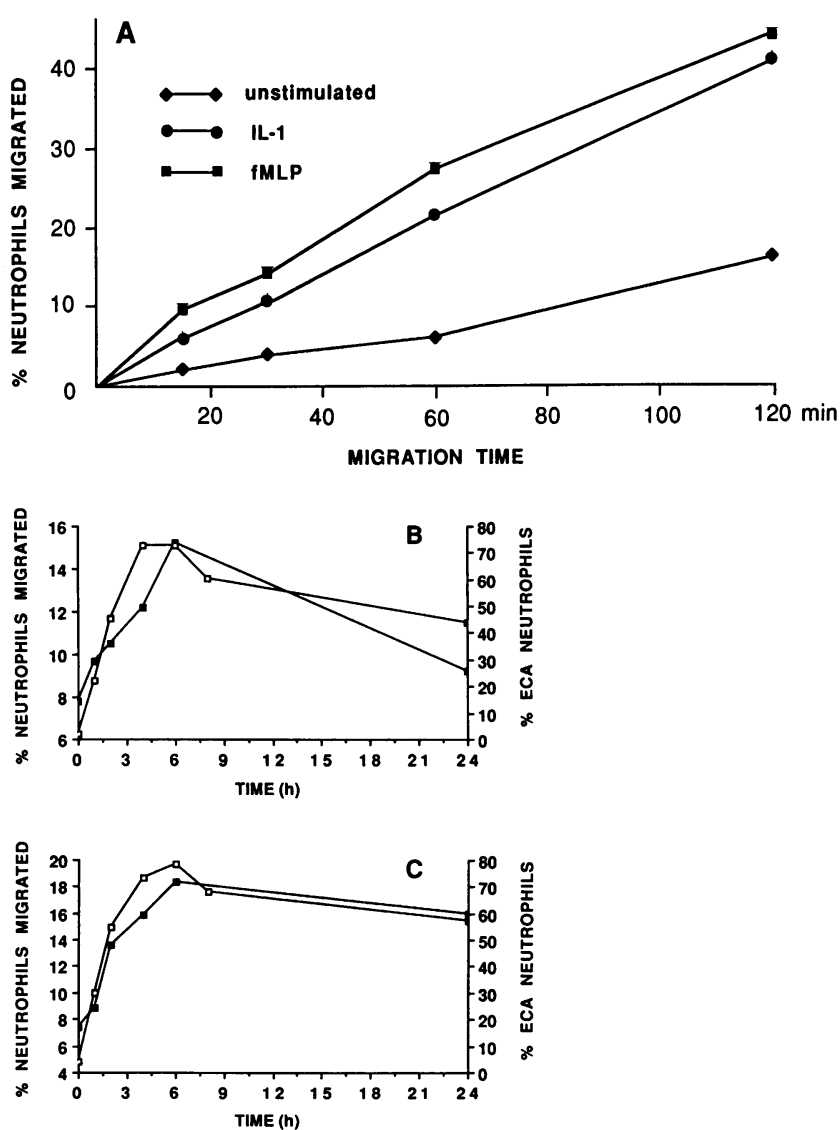

Figure 5. (A) Time course of neutrophil random migration across unstimulated and IL-1-stimulated HUVE monolayers $(1 \mathrm{U} / \mathrm{ml})$ compared to chemotaxis towards FMLP $\left(10^{-8} \mathrm{M}\right) .(B)$ Interaction of neutrophils with HUVE in the dish assay (open squares) following preincubation for indicated periods of time with IL-1 $(2 \mathrm{U} / \mathrm{ml})$ compared to the amount of HUVE layer transmigration during $60 \mathrm{~min}$ in the Boyden chamber assay (black squares). $(C)$ Interaction of neutrophils with HUVE in the dish assay (open squares) following preincubation for indicated periods of time with TNF $(50 \mathrm{ng} / \mathrm{ml})$ compared to the amount of HUVE layer transmigration during $60 \mathrm{~min}$ in the Boyden chamber assay (black squares). Each point represents the mean of duplicate determinations of one out of three congruent experiments.

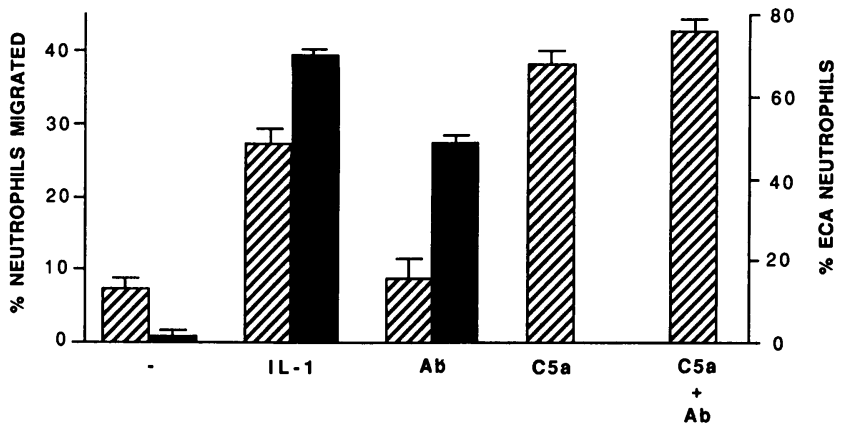

Figure 6. Independence of neutrophil binding to HUVE monolayers from subsequent monolayer penetration. Determination of ECA neutrophils (black bars; dish assay) and transendothelial migration of neutrophils (hatched bars; monolayer-on-filter system) were made from the same batch of neutrophils and endothelial cells simultaneously. HUVE monolayers were preincubated with medium (-) or medium containing IL-1 $(1 \mathrm{U} / \mathrm{ml})$ for $2 \mathrm{~h}$. For Fc-mediated binding of neutrophils to HUVE (Ab), rabbit anti-human- $\beta_{2}$-microglobulin antibody (final dilution 1:50) was added to the upper compartment of the Boyden chamber. As a control, neutrophil transendothelial migration was performed along a transendothelial gradient of $\mathrm{C} 5 \mathrm{a}(0.4 \mu \mathrm{g} / \mathrm{ml})$ in the presence or absence of the antibody (C5a and $\mathrm{C} 5 \mathrm{a}+\mathrm{Ab}$, respectively). Bars denote mean $\pm \mathrm{SD}$ of triplicate determinations of one of three identical experiments.

thelium-dependent neutrophil transmigration into an initial anchoring step followed by active neutrophil migration.

In the same context, it is important to note that IL-1 and TNF priming of HUVE in the dish assay resulted in an impressive increase of shear stress-resistant lymphocyte-HUVE interaction from a control value of $5 \pm 0.1 \%$ to $31 \pm 1 \%$ ECA lymphocytes for IL-1 and to $31 \pm 0.7 \%$ ECA lymphocytes for TNF (mean \pm SE of three experiments), while such an interaction was obviously not accompanied by complete layer transmigration by these cells (Fig. 12).

Additional experiments corroborate our morphological evidence that IL-1- or TNF-provoked transendothelial neutrophil passage stimulation is not caused by leakiness due to structural disturbance of the monolayer, as IL-1 $(4 \mathrm{U} / \mathrm{ml})$ or TNF $(50 \mathrm{ng} / \mathrm{ml})$ activation of HUVE for $4 \mathrm{~h}$ was not accompanied by increased permeability of the layer for ${ }^{125} \mathrm{I}$-albumin or for erythrocytes (Fig. 12).

Table I. Search for Neutrophil Chemotactic Activity Secreted by IL-1-Activated HUVE Monolayers

\begin{tabular}{lllr}
\hline & \multicolumn{3}{c}{ Migration assay } \\
\cline { 2 - 3 } HUVE preincubation & \multicolumn{3}{c}{$90 \mathrm{~min}$} \\
\cline { 2 - 4 } \multicolumn{1}{c}{$60 \mathrm{~min}$} & & \multicolumn{2}{c}{ Compartment } \\
\cline { 2 - 4 } Medium & Upper & Lower & \% PMN migrated* \\
IL-1 (1 U/ml) & PMN & HIP & $2.6 \pm 0.1$ \\
Medium & PMN & HIP & $2.6 \pm 0.2$ \\
& PMN & HIP-FMLP & $12.6 \pm 2.4$
\end{tabular}

* Numbers denote percentage of totally applied neutrophils (PMN). Means \pm SD of triplicates of a representative experiment are shown. For further details see Methods. 


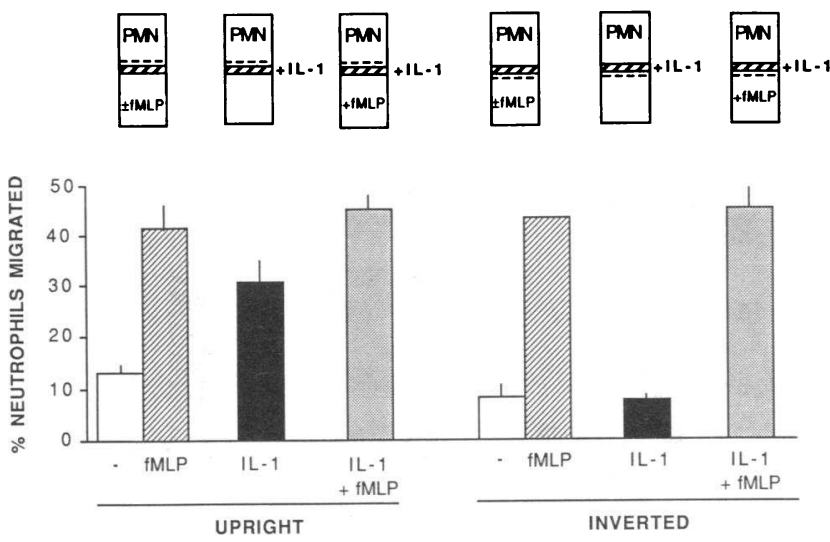

Figure 7. Polarization of transendothelial neutrophil traffic. Random migration across unstimulated $(-)$ and IL-1 stimulated HUVE monolayers (IL-1) compared to chemotaxis toward FMLP $\left(10^{-8} \mathrm{M}\right.$; FMLP) carried out in parallel with HUVE monolayers grown on the upper (upright) and on the lower surface of the Nuclepore filter membrane (inverted). Chemotactic response to FMLP $\left(10^{-8} \mathrm{M}\right)$ during IL-1-provoked transmigration shows retained neutrophil motility (IL-1 + FMLP). Results given in this figure are from one of five experiments using the same batch of neutrophils and endothelial cells in each experiment. Bars denote mean \pm SD of triplicate determinations (SD $<1 \%$ of mean are not shown).

\section{Discussion}

Experimental in vivo observations on "leukodiapedesis" have first been made almost 150 years ago $(31,32)$. Since then, this term, designating emigration of leukocytes from the vascular bed to the inflammatory focus, has remained descriptive (5), and mechanisms governing this process are largely unknown (33-35). Application of in vitro models allowing to study transendothelial neutrophil migration quantitatively by using rather well controllable monolayers of endothelial cells should provide new insight into such mechanisms.

Assuming that the vascular endothelium could play an active role in regulation of transendothelial neutrophil traffic and guided by the recent finding that IL-1 and TNF act as inducers of procoagulant activity (36) and leukocyte adherence $(15,37)$, short-time preincubation experiments using these monokines were started. Related to the experience that even activated neutrophils, which display intense spreading

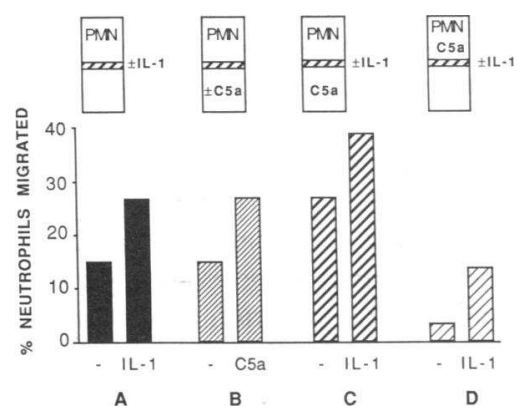

Figure 8. Vectorial behavior of the IL-1-stimulated transendothelial neutrophil traffic. $(A)$ Random migration across unstimulated $(\longrightarrow)$ and IL-1-activated HUVE monolayer (IL-1), and (B) chemotaxis in response to $\mathrm{C} 5 \mathrm{a}(50 \mathrm{ng} / \mathrm{ml})$ in comparison to $(C)$ a superimposed positive or

(D) a negative C5a gradient. Results given in this figure are from one of three experiments using the same batch of neutrophils and endothelial cells in each experiment. Bars denote mean of triplicate determinations (SD were found to be $<10 \%$ of each represented value).
Table II. Effect of Different Inflammatory Mediators on Induction of Endothelium-dependent Neutrophil Immigration into HUVE Monolayers on Culture Dishes

\begin{tabular}{|c|c|c|}
\hline $\begin{array}{l}\text { Preincubation } \\
\text { of HUVE }\end{array}$ & $\rightarrow \quad \begin{array}{c}\text { Coincubation of } \\
\text { HUVE + neutrophils }\end{array}$ & $\rightarrow \begin{array}{c}\text { ECA } \\
\text { neutrophils* }\end{array}$ \\
\hline $\begin{array}{c}60 \text { min } \\
\text { (except as indicated) }\end{array}$ & $30 \mathrm{~min}$ & $\begin{array}{c}\% \text { relative } \\
\text { activity }\end{array}$ \\
\hline IL-1 (1 U/ml) & & 100 \\
\hline TNF (50 ng/ml) & & 145 \\
\hline $\operatorname{IL}-2(1,000 \mathrm{U} / \mathrm{ml})$ & & 4 \\
\hline$\gamma$-Interferon $(10,000 \mathrm{U} / \mathrm{ml})$ & & 0 \\
\hline PDGF $(10 \mathrm{U} / \mathrm{ml})$ & & 0 \\
\hline Thrombin (1 U/ml; $5 \mathrm{~min})$ & & 0 \\
\hline Histamine $\left(10^{-3} \mathrm{M} ; 15 \mathrm{~min}\right)$ & & 0 \\
\hline $\operatorname{PAF}\left(10^{-4} \mathrm{M}\right)$ & & $\mathbf{0}$ \\
\hline $\operatorname{LTB}_{4}\left(10^{-5} \mathrm{M}\right)$ & & 0 \\
\hline
\end{tabular}

* Results determined as ECA neutrophils (having resisted the highshear stress wash procedure) and expressed as percent relative activity compared to the IL-1 effect $=100 \%$.

and metabolic activation on artificial substrates, showed only loose attachment to HUVE monolayers (19), the initial observation by light microscopy of a shear stress resistant binding of neutrophils to IL-1-primed monolayers was quite surprising. An extensive morphologic study of IL-1- (and TNF)-primed HUVE, with examples of it presented here, revealed that most of these ECA neutrophils, after approaching cellular margins, had in fact passed through the endothelial layer at intercellular junctions. This type of junctional transendothelial passage, known as habitual way of neutrophil emigration (8) and recently also described for FMLP-induced neutrophil migration across monolayers of bovine microvascular endothelial cells (35) is clearly distinct from transcellular passage of mature blood cells from bone marrow tissue into marrow sinuses (38).
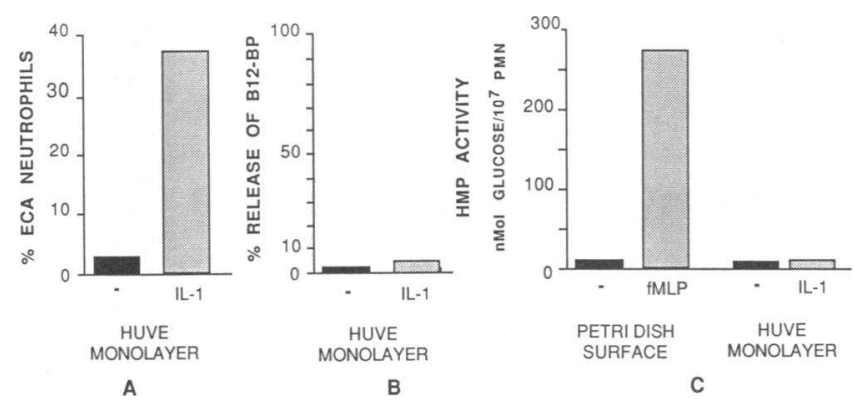

Figure 9. Metabolic activity of ECA neutrophils. (A) Amount of ECA neutrophils following preincubation with medium $(-)$ or medium containing IL-1. (B) Release of $B_{12}$ binding protein (B12BP) in the supernatant of standard HUVE/neutrophil incubations as given in $\mathrm{A}$. $(C)$ Hexose monophosphate shunt activity on plain tissue culture dishes, as a negative control (-); on plain culture dishes in the presence of FMLP $(2.5 \mu \mathrm{M})$ as a positive control; on HUVE preincubated with medium alone $(-)$ and with IL-1 (IL-1). Results given in this figure are typical for three experiment using the same batch of neutrophils and endothelial cells. Bars denote mean of triplicate determinations (SD were found to be $<10 \%$ of each represented value). 


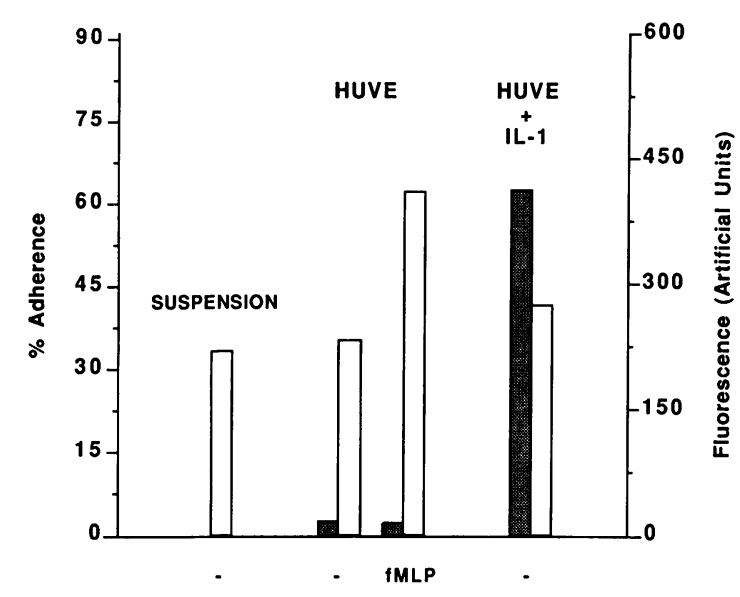

Figure 10. Neutrophil association with endothelial monolayers does not cause upregulation of Mac-1 surface expression. Neutrophils unstimulated $(-)$ or processed for maximal Mac-1 surface expression by previous FMLP $\left(2.5 \times 10^{-6} \mathrm{M}\right)$-induced adherence to plastic dishes (for details see Methods) were suspended in HIP and were overlayered onto HUVE monolayers preincubated for $2 \mathrm{~h}$ with medium (HUVE) or medium containing $1 \mathrm{U} / \mathrm{ml}$ of IL-1 (HUVE + IL-1). Standard assay conditions were used to determine the percentage of ECA neutrophils (gray bars) and cytofluorometric determination of mean fluorescence intensity (open bars) was performed in parallel under identical conditions. Bars denote mean \pm SD (ECA neutrophils) of triplicate determinations ( $\mathrm{SD}<0.5 \%$ is not shown). Vitality was verified by trypan-blue exclusion $(>88 \%)$ and functional integrity was tested in adhesion experiments carried out in parallel on plastic dishes. The results are typical for three experiments using MAb 60.3 and MAb M1/70 (not shown).

Guided by these morphologic facts, we embarked on a functional analysis that differentiates layer transmigration from mere attachment. By means of a specifically adapted

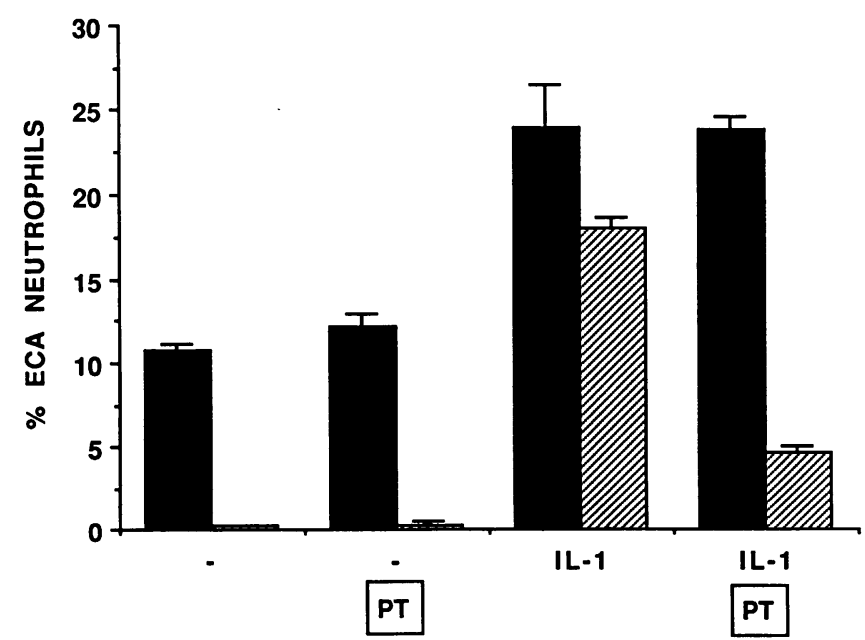

Figure 11. Separation of mere neutrophil adhesion from neutrophil interaction leading to layer penetration in the dish assay system. Neutrophils, pretreated with pertussis toxin (PT; $50 \mathrm{ng} / \mathrm{ml}$ for $2 \mathrm{~h}$ at $37^{\circ} \mathrm{C}$ ), and untreated neutrophils were tested for their ability to undergo shear stress-stable interaction with IL-1-activated (IL-1) versus nonactivated (-) HUVE. Shear stress stability was tested using the standard wash procedure (hatched bars) and was compared to simple decantation (black bars) to avoid shear stress (for details, see Methods). Bars denote mean \pm SD of triplicate determinations ( $\mathrm{SD}<1 \%$ of mean are not shown).

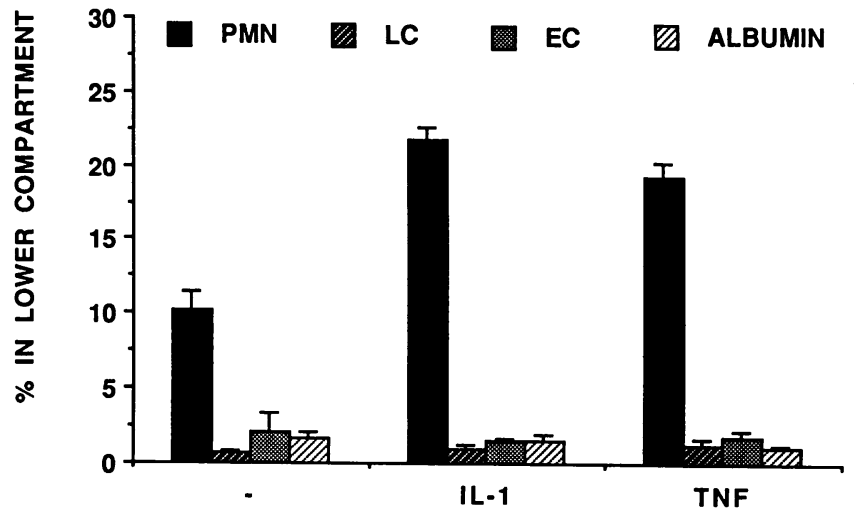

Figure 12. Permeability testing of IL-1- or TNF-activated HUVE monolayers. HUVE monolayers grown on Nuclepore membranes (5- $\mu \mathrm{m}$ pore size) were preincubated for $4 \mathrm{~h}$ with medium (-), medium containing IL-1 $(4 \mathrm{U} / \mathrm{ml})$ or TNF $(50 \mathrm{ng} / \mathrm{ml})$. Neutrophils $\left(P M N ; 10^{6}\right)$, lymphocytes $\left(L C ; 10^{6}\right)$, erythrocytes $\left(E C ; 10^{7}\right)$ or ${ }^{125} \mathrm{I}$-albumin $(A L B U M I N)$ in HIP were then added to the upper compartment and incubations were continued for $90 \mathrm{~min}$ (for details see Methods). Bars denote mean \pm SD of triplicate determinations, typical for three experiments.

HUVE monolayer dish assay, and, more comprehensible, with a two-compartment monolayer-on-filter system, we made the novel observation that cultured human endothelial cells can be induced by IL-1 and TNF to enhance transendothelial neutrophil traffic in the absence of an externally applied chemotactic gradient. It is important to recognize that IL-1 and TNF-induced passage stimulation is quantitatively comparable to chemotaxin-induced neutrophil transmigration. Moreover, our data suggest that the described promotion of neutrophil layer penetration is a unique feature of IL-1- and TNF-induced neutrophil-endothelium interaction and cannot be viewed as a simple consequence of mere neutrophil attachment stimulation to the endothelial cell lining (e.g., as induced by means of $\mathrm{Fc}$-mediated neutrophil attachment or adhesion enhancement due to high-dose stimulation of neutrophils with FMLP [39]; cf. Fig. 6). In the case of short time priming with thrombin, the described enhancement of neutrophil adhesion (40) was shear stress-labile due to the superficial limitation of this interaction and was not leading to augmented neutrophil layer penetration.

The endothelial origin of this phenomenon is characterized by its dependence on de novo protein synthesis and susceptibility to trypsin. In contrast to the prostaglandin E2-mediated effect of IL-1 on fever induction and muscle proteolysis (41), the above phenomenon is not blocked by indomethacin. Moreover, high-dose corticosteroids were not able to influence the IL-1-induced activation of neutrophil transmigration, a fact recently confirmed by others (42).

Since, in vivo, there is virtually strict one-way traffic for neutrophils, and the endothelial barrier is a point-of-no-return for these cells (43), we approached the question as to whether IL-1 and TNF might take command of such traffic regulation. This was accomplished by comparison with an upside-down modification of the monolayer-on-filter assay culturing HUVE to confluency on the lower surface of the micropore filter. Under these conditions, IL-1-primed HUVE lost their potency of transmigration enhancement in spite of retained neutrophil motility as shown by their chemotactic responsive- 
ness to FMLP. It is important to note that virtually comparable random as well as chemotaxin-stimulated migration were observed in both, the inverted and the upright system (Fig. 7). This strongly indicates that the lack of transmigration enhancement of IL-1 in the inverted system is not due to system-inherent passage hindrance of neutrophils. In addition, the influence of a superimposed positive or negative C5a gradient on IL-1-primed HUVE monolayers in the upright system was tested in order to further corroborate the above interpretation of our findings (Fig. 8). These results, together with the morphological aspects, support the concept of the vectorial nature of IL-1-enhanced transendothelial neutrophil traffic.

Since chemotactic activity produced by endothelial cells, spontaneously (10) or in response to thiourea (11), has been reported, attempts were made to detect endothelial chemotaxin production induced by IL-1. Negative findings in these experiments make neutrophil attraction by a soluble chemotactic gradient improbable. Furthermore, the fact that IL-1 was-in our hands-devoid of any neutrophil chemotactic activity, a finding now confirmed by others (44), together with the lack of an IL-1 effect when this compound was added during the HUVE-neutrophil coincubation step, define IL-1 as an agent active exclusively on endothelial cells.

According to our interpretation, two further points corroborate the notion that neutrophil attachment to and passage through the endothelial layer are indeed two separable, not necessarily linked functional entities. Firstly, it is worth mentioning that, with respect to lymphocytes, IL-1-induced attachment stimulation, a phenomenon confirming earlier observations (45), was not followed by passage stimulation of these cells (Fig. 12). Secondly, separation of shear stress-labile neutrophil adhesion from shear stress-stable interaction ultimately leading to endothelial layer penetration by pretreatment of neutrophils with pertussis toxin (Fig. 11) allows to conclude that an active locomotory machinery of neutrophils is necessary to respond to this endothelial challenge, or, in other words, a passive drag-through mechanism is hardly involved in this cellular transposition phenomenon. On the other hand, the formation of neutrophil-endothelium adhesion sites seems crucial as a primary anchoring step for neutrophils $(46,47)$. We propose that such anchoring is a prerequisite for neutrophils to respond to a putative surface bound "chemotactic gradient" along which the cells might move in a manner that has been called "haptotaxis" $(48,49)$. Whether this two functional steps are based on separate structural entities coexpressed on endothelial cells in response to IL-1 and TNF or whether the binding as well as the neutrophil passage guiding principle is structurally related to one single and inducible endothelial membrane protein, is presently unknown. Despite similarities of functional observations (Fig. 5, $B$ and $C$ vs. references $15,17,47$ ), it remains to be defined as to whether endothelial surface structures responsible for IL-1 - and TNFinduced neutrophil attachment to endothelium as they are presently characterized $(17,47)$ correspond to the neutrophil passage guiding principle evolving from our experimental model.

The demonstration that intradermally injected IL-1 leads -despite its chemotactic inertness-to local neutrophil extravasation $(50,51)$, is a first hint to an in vivo correlate of our in vitro findings but does not exclude additional involvement of IL-1-induced chemotactic factors in leukocyte recruitment. Moreover, strong evidence is turning up that IL-1 is a common final mediator of endotoxin-induced neutrophil emigration in vivo $(51,52)$ including the local Shwartzmann reaction $(53$, 54). Whether IL-1 and TNF as novel regulators of neutrophil kinetics play an essential role in the pathogenesis of vascular diseases or whether they are mainly responsible for directing neutrophil egress into inflammatory tissue regions is presently unknown. Our finding that neutrophils crossing the HUVE monolayer in response to IL-1 stimulation are in a metabolically calm state (Fig. 9; no oxidative burst activation, no granule content release) favors the latter view. These facts are further corroborated by the lack of Mac-1 (CD11b/CD18) upregulation (Fig. 10), a leukocyte surface antigen, which is involved in the association of neutrophils to endothelium (37) and in their adhesion to plastic as well as in the activation and promotion of other cellular functions (personal observations; 55-57).

\section{Acknowledgments}

We thank Dr. K. Mansour for his help in preparing electron micrographs, and C. Wolfer for her excellent technical assistance. We acknowledge the generous supply of recombinant human IL-1 by Dr. Stein and Dr. Lomedico, Hoffmann-La Roche, Inc. Thanks are due to Dr. M. Patarroyo, Karolinska Institute, Stockholm, Sweden, for kindly providing monoclonal antibody 60.3 .

This work was supported in part by the Swiss National Science Foundation grant No. 3.850.85 and the Krebs-Liga des Kt. Zurich.

\section{References}

1. Beesley, J. E., J. D. Pearson, J. S. Carleton, A. Hutchings, and J. L. Gordon. 1978. Interaction of leukocytes with vascular cells in culture. J. Cell. Sci. 33:85-101.

2. Hoover, R. L., R. T. Briggs, and M. J. Karnovsky. 1978. The adhesive interaction between polymorphonuclear leukocytes and endothelial cells in vitro. Cell. 14:423-428.

3. Hoover, R. L., R. Folger, W. A. Haering, B. R. Ware, and M. J. Karnovsky. 1980. Adhesion of leukocytes to endothelium: role of divalent cations, surface charge, chemotactic agents and substrate. $J$. Cell. Sci. 45:73-86.

4. Wall, R. T., S. L. Cooper, and I. C. Kosek. 1982. The influence of exogenous fibronectin on blood granulocyte adherence to vascular endothelium in vitro. Exp. Cell. Res. 140:105-109.

5. Marchesi, V., and H. Florey. 1960. Electron micrographic observations on the emigration of leukocytes. J. Exp. Physiol. 45:343348.

6. Shaw, J. O. 1980. Leukocytes in chemotactic fragment-induced lung inflammation. Vascular emigration and alveolar surface migration. Am. J. Pathol. 101:283-302.

7. Thorgeirsson, G., and A. L. Robertson. 1979. The vascular endothelium-pathobiologic significance. Am. J. Pathol. 93:803-847.

8. Harlan, J. M. 1985. Leukocyte-endothelial interactions. Blood. 65:513-525.

9. Tonnesen, M., L. Smedly, A. Goins, and P. Henson. 1982. The microvasculature in inflammation. Interaction between neutrophils and vascular endothelial cells. Agents Actions. 11(Suppl. 1):25-38.

10. Mercandetti, A. J., T. A. Lane, and M. E. Colmerauer. 1984. Cultured human endothelial cells elaborate neutrophil chemoattractants. J. Lab. Clin. Med. 104:370-380.

11. O'Brien, R. F., M. P. Seton, J. S. Makarski, D. M. Center, and S. Rounds. 1984. Thiourea causes endothelial cells in tissue culture to produce neutrophil chemoattractant activity. Am. Rev. Respir. Dis. 130:103-109.

12. Gimbrone, M. A., A. F. Brock, and A. I. Schafer. 1984. Leukotriene B4 stimulates polymorphonuclear leukocyte adhesion to cultured vascular endothelial cells. J. Clin. Invest. 74:1552-1555. 
13. Hoover, R. L., M. J. Karnovsky, K. F. Austen, E. J. Corey, and R. A. Lewis. 1984. Leukotriene B4 action on endothelium mediates augmented neutrophil/endothelial adhesion. Proc. Natl. Acad. Sci. USA. 81:2191-2193.

14. Zimmerman, G. A., and H. R. Hill. 1984. Inflammatory mediators stimulate granulocyte adherence to cultured endothelial cells. Thromb. Res. 35:203-217.

15. Bevilacqua, M. P., J. S. Prober, M. E. Wheeler, R. S. Cotran, and M. A. Gimbrone. 1985. Interleukin-1 acts on cultured human vascular endothelium to increase adhesion of polymorphonuclear leukocytes, monocytes, and related leukocyte cell lines. J. Clin. Invest. 76:2003-2011.

16. Gamble, J. R., J. M. Harlan, S. J. Klebanoff, and M. A. Vadas. 1985. Stimulation of the adhesion of neutrophils to umbilical vein endothelium by human recombinant tumor necrosis factor. Proc. Natl. Acad. Sci. USA. 82:8667-8671.

17. Pober, J. S., M. P. Bevilaqua, D. L. Mendrick, L. A. Lapierre, W. Fiers, and M. A. Gimbrone, Jr. 1986. Two distinct monokines, interleukin 1 and tumor necrosis factor, each independently induce biosynthesis and transient expression of the same antigen on the surface of cultured human vascular endothelial cells. J. Immunol. 136:1680-1686.

18. Jaffe, E. A., R. L. Nachman, C. G. Becker, and C.-R. Minick. 1973. Culture of human endothelial cells derived from umbilical veins. J. Clin. Invest. 52:2745-2756.

19. Fehr, J., R. Moser, D. Leppert, and P. Groscurth. 1985. Antiadhesive properties of biological surfaces are protective against stimulated granulocytes. J. Clin. Invest. 76:535-542.

20. Watkins, M. T., J. B. Sharefkin, R. Zajtchuk, T. M. Maciag, P. A. D'Amore, U. S. Ryan, H. Van Wart, and N. M. Rich. 1984. Adult human saphenous vein endothelial cells. Assessment of their reproductive capacity for use in endothelial seeding of vascular prostheses. J. Surg. Res. 36:588-596.

21. Dahinden, C., C. Galanos, and J. Fehr. 1983. Granulocyte activation by endotoxin. Part I. J. Immunol. 130:857-862.

22. Dahinden, C., C. Galanos, and J. Fehr. 1983. Granulocyte activation by endotoxin. Part II. J. Immunol. 130:863-868.

23. Fehr, J., and H. S. Jacob. 1977. In vitro granulocyte adherence and in vivo margination: two associated complement-dependent functions. J. Exp. Med. 146:641-652.

24. Schroeter, D., E. Spiess, N. Paweletz, and R. Denke. 1984. Procedure for rupture-free preparation on confluently grown monolayer cells for scanning electron microscopy. J. Electron. Microsc. Techn. 1:219-225.

25. Fernandez, H. N., and T. E. Hugli. 1976. Partial characterization of human C5a anaphylatoxin. I. Chemical description of the carbohydrate polypeptide portion of human C5a. J. Immunol. 117:16881694.

26. Hugli, T. E., C. Gerard, M. Kawahara, M. E. Scheetz, R. Barton, St. Briggs, G. Koppel, and S. Russel. 1981. Isolation of three separate anaphylatoxins from complement-activated human serum. Mol. Cell. Biochem. 41:59-66.

27. Patarroyo, M., and I. J. Ansotegui. 1987. Effect of monoclonal antibodies of nonlineage, CD11 and CD18 on phorbol ester-induced adhesion among different leukocytes. In Leukocyte Typing III. A. J. McMichael, editor. Oxford University Press, Oxford/England. 839-844.

28. Beesley, J. E., J. D. Pearson, A. Hutchings, J. S. Carleton, and J. L. Gordon. 1979. Granulocyte migration through endothelium in culture. J. Cell Sci. 38:237-248.

29. Dinarello, C. A., J. G. Cannon, J. W. Mier, H. A. Bernheim, G. LoPreste, D. L. Lynn, R. N. Love, A. C. Webb, P. E. Auron, R. C. Reuben, A. Rich, S. M. Wolff, and S. D. Putney. 1986. Multiple biological activities of human recombinant interleukin 1. J. Clin. Invest. 77:1734-1739.

30. Spangrude, G. J., F. Sacchi, H. R. Hill, D. E. Van Epps, and R. A. Daynes. 1985. Inhibition of lymphocyte and neutrophil chemotaxis by pertussis toxin. J. Immunol. 135:4135-4143.
31. Addison, W. 1843. Experimental and practical researches on the structure and function of blood corpuscules on inflammation and on the origin and nature of tubercles in the lungs. Trans. Prov. Med. Surg. Assoc. 11:236-306.

32. Waller, A. V. 1846. Microscopic observations on the perforation of the capillaries by corpuscles of the blood, and on the origin of mucus and pus globules. Phil. Mag. 29:271-287.

33. Meyrick, B., L. H. Hoffman, and K. L. Brigham. 1984. Chemotaxis of granulocytes across bovine artery intimal explants without endothelial cell injury. Tissue Cell. 16:1-16.

34. Taylor, R. F., T. H. Price, S. M. Schwartz, and D. C. Dale. 1981. Neutrophil-endothelial cell interactions on endothelial monolayers grown on micropore filter. J. Clin. Invest. 67:584-587.

35. Furie, M. B., B. L. Napstek, and S. C. Silverstein. 1987. Migration of neutrophils across monolayers of cultured microvascular endothelial cells. J. Cell Sci. 88:161-175.

36. Bevilaqua, M. P., J. S. Pober, G. R. Majeau, R. S. Cotran, and M. A. Gimbrone, Jr. 1984. Interleukin 1 (IL-1) induces biosynthesis and cell surface expression of procoagulant activity in human vascular endothelial cells. J. Exp. Med. 160:618-624.

37. Pohlman, T. H., K. A. Stanness, P. G. Beatty, H. D. Ochs, and J. M. Harlan. 1986. A.n endothelial cell surface factor(s) induced in vitro by lipopolysaccharide, interleukin 1 , and tumor necrosis factor- $\alpha$ increases neutrophil adherence by a CDw 18-dependent mechanism. $J$. Immunol. 136:4548-4553.

38. Tavassoli, M. 1979. The marrow-blood barrier. Br. J. Haematol. 41:297-302.

39. Tonnesen, M. G., L. A. Smedly, and P. M. Henson. 1984. Neutrophil-endothelial cell interactions. Modulation of neutrophil adhesiveness induced by complement fragments $\mathrm{C} 5 \mathrm{a}$ and $\mathrm{C} 5 \mathrm{a}$ desarg and formyl-methionyl-leucyl-phenylalanine in vitro. J. Clin. Invest. 74:1581-1592.

40. Zimmerman, G. A., T. M. McIntyre, and S. M. Prescott. 1985. Thrombin stimulates the adherence of neutrophils to human endothelial cells in vitro. J. Clin. Invest. 76:2235-2246.

41. Baracos, V., H. P. Rodemann, C. A. Dinarello, and A. L. Goldberg. 1983. Stimulation of muscle protein degradation and prostaglandin $\mathrm{E}_{2}$ release by leukocytic pyrogen (interleukin-1). A mechanism for the increased degradation of muscle protein during fever. $N$. Engl. J. Med. 308:553-558.

42. Bochner, B. S., B. K. Rutledge, and R. P. Schleimer. 1987. Interleukin-1 production by human lung tissue. II. Inhibition by antiinflammatory steroids. J. Immunol. 139:2303-2307.

43. Boggs, D. R. 1967. The kinetics of neutrophilic leukocytes in health and disease. Semin. Hemalol. 4:359-386.

44. Georgilis, K., Ch. Schafer, C. A. Dinarello, and M. S. Klempner. 1987. Human recombinant interleukin-1-beta has no effect on intracellular calcium or on functional responses of human neutrophils. J. Immunol. 138:3403-3407.

45. Cavender, D. E., D. O. Harskard, B. Joseph, and M. Ziff. 1986. Interleukin-1 increases the binding of human $B$ and $T$ lymphocytes to endothelial cell monolayers. J. Immunol. 136:203-207.

46. Pohlman, T. H., K. A. Stanness, P. G. Beatty, H. D. Ochs, and J. M. Harlan. 1986. An endothelial cell surface factor(s) induced in vitro by lipopolysaccharide, interleukin-1, and tumor necrosis factor-a increases neutrophil adherence by a CDw18-dependent mechanism. $J$. Immunol. 136:4548-4553.

47. Bevilacqua, M. P., J. S. Pober, D. L. Mendrick, R. S. Cotran, and M. A. Gimbrone, Jr. 1987. Identification of an inducible endothelial-leukocyte adhesion molecule. Proc. Natl. Acad. Sci. USA. 84:9238-9242.

48. Carter, S. B. 1965. Principles of cell motility: the direction of cell movement and cancer invasion. Nature (Lond.). 208:1183-1187.

49. Dierich, M. P., D. Wilhelmi, and G. Till. 1977. Essential role of surface-bound chemoattractant in leukocyte migration. Nature (Lond.). 270:351-352.

50. Granstein, R. D., R. Margolis, S. D. Mizel, and D. N. Sauder. 1986. In vivo inflammatory activity of epidermal cell-derived thymo- 
cyte activating factor and recombinant interleukin 1 in the mouse. $J$. Clin. Invest. 77:1020-1027.

51. Issekutz, A. C., P. Megyeri, and T. B. Issekutz. 1987. Role for macrophage products in endotoxin-induced polymorphonuclear leukocyte accumulation during inflammation. Lab. Invest. 56:49-59.

52. Cibulsky, M. L., I. G. Colditz, and Z. H. Movat. 1986. The role of interleukin 1 in leukocyte emigration induced by endotoxin. Am. J. Pathol. 124:367-372.

53. Beck, G., G. S. Habicht, J. L. Benach, and F. Miller. 1986. Interleukin-1: a common endogenous mediator of inflammation and the local Shwartzman reaction. J. Immunol. 136:3025-3031.

54. Movat, H. Z., C. E. Burrowes, M. I. Cibulsky, and C. A. Dinarello. 1987. Acute inflammation and a Shwartzman-like reaction induced by interleukin- 1 and tumor necrosis factor. Synergistic action of the cytokines in the induction of inflammation and microvascular injury. Am. J. Pathol. 129:463-476.

55. Arnaout, M. A., H. Spits, C. Terhorst, J. Pitt, and R. F. Todd III. 1984. Deficiency of a leukocyte surface glycoprotein (LFA-1) in two patients with Mol deficiency. Effects of cell activation on Mol/ LFA-1 surface expression in normal and deficient leukocytes. J. Clin. Invest. 74:1291-1300.

56. O'Shea, J. J., E. J. Brown, B. E. Seligmann, J. A. Metcalf, M. M. Frank, and J. I. Gallin. 1985. Evidence for distinct intracellular pools of receptors for $\mathrm{C} 3 \mathrm{~b}$ and $\mathrm{C} 3 \mathrm{bi}$ in human neutrophils. J. Immunol. 134:2580-2587.

57. Todd, R. F., III, M. A. Arnaout, R. E. Rosin, C. A. Crowley, W. A. Peters, and B. M. Babior. 1984. Subcellular localization of the large subunit of Mol (Mola; formerly gp 110), a surface glycoprotein associated with neutrophil adhesion. J. Clin. Invest. 74:1280-1290. 